\title{
An IoT fueled DSS for MOL Marine Auxiliaries Management
}

\author{
Moritz von Stietencron $^{1 *}$, Karl A. Hribernik ${ }^{1}$, Carl Christian Røstad ${ }^{2}$, Bjørnar \\ Henriksen $^{2}$, Klaus-Dieter Thoben ${ }^{1,3}$ \\ ${ }^{1}$ BIBA - Bremer Institut für Produktion und Logistik GmbH at the University of Bremen, \\ Hochschulring 20, 28359 Bremen, Germany \\ \{sti,hri,tho\}@biba.uni-bremen.de \\ ${ }^{2}$ SINTEF Technology and Society, S.P. Andersens vei 5, N-7465 Trondheim, Norway \\ \{carl.c.rostad,bjornar.henriksen\}@sintef.no \\ ${ }^{3}$ Faculty of Production Engineering, University of Bremen, Badgasteiner Straße 1, 28359 \\ Bremen, Germany
}

\begin{abstract}
The producers of marine auxiliaries face the challenge, that they need to adapt their middle-of-life activities to the otherwise defined and often not well communicated schedules of the ships, which are carrying their products. This paper presents both the methodological approach to a solution and its prototypical implementation in a specific use case. The solution presented is utilizing the Internet of Things (IoT) and the data that is constantly being produced by the ships through the Automatic Identification System (AIS) to help overcome this problem.
\end{abstract}

Keywords: Internet of Things $\bullet$ AIS $\bullet P L M \bullet M O L \bullet$ Marine Industry

\section{Introduction}

The management of middle-of-life (MOL) actions is a challenging task for the producers of marine auxiliaries. While this may be found true for many knowledge intensive products, there are a couple of unique restrictions that apply in the marine domain. However, with the wake of the Internet of Things (IoT) also new possibilities for overcoming these problems are emerging.

In this paper we are presenting an IoT based approach to intelligent management of MOL activities for marine auxiliaries and their producers. Based on the general motivation, related work and presentation of the methodology, a specific implementation for a decision support system based on data from the AIS (Automatic Identification System) network is presented. The paper concludes with a summary of the findings and an outlook to future work. 


\section{Background and Motivation}

The suppliers of auxiliary components in the shipbuilding domain share the problem, that while their products may be important to the operation of the ship, they regularly do not have a high enough significance to influence possible schedules and locations for middle of life (MOL) activities, such as maintenance, repair and overhaul (MRO) on their products. With regards to the tight operation schedules of their containing product, the ship, the auxiliaries' suppliers are thus at the mercy of the shipowning company.

As a direct influence on the ships schedule for MOL activities is not possible, the auxiliaries producers have to adapt their actions to the ships schedules. The traditional practise requires the producers to manually identify the products which require service or for which additional offerings can be made and contact the respective shipowning companies to ask for available time slots. These time slots have are usually during cargo handling in port. An overview of these information over multiple shipowners and ports to streamline schedules is often already outdated before it has been fully compiled in the traditional manner.

Due to these problems some producers of marine auxiliaries have begun to use AIS based online systems like MarineTraffic ${ }^{1}$ to track the relevant ships and identify their next port calls. However, this practise either binds the users to the consumer oriented user interface offered for free or at little costs by the service providers or invokes high costs for data acquisition and integration into the enterprise systems.

The solution proposed in this paper tries to overcome these problems and offer a cost effective and efficient way for marine auxiliaries producers to manage MOL activities on their products.

\section{Related Work}

This section gives an overview of the related work of the scientific community on the main technologies and topics relevant to the methodology described in the succeeding chapter.

\subsection{PLM - Product Lifecycle Management}

The production engineering perspective on Product Lifecycle Management (PLM) [1] often divides the products lifecycle into the following three main phases: beginningof-life (BOL), middle-of-life (MOL) and end-of-life (EOL). [2] While the BOL with steps such as product development, production and distribution and the EOL with the reverse logistics are regularly of little interest to the customer or end user, the MOL phase and its contents are in direct interaction with the user. [3]

${ }^{1}$ http://www.marinetraffic.com/ 
This high degree of user control imposes a barrier to frequent interaction of product and producer. This is even increased in control and security sensitive industries like the marine sector.

However, for closed-loop PLM it is crucial to combine information flows of as many product phases as possible. [4] Thus the integration of the MOL phase as the regularly longest phase is of high importance.

\subsection{Servitization}

The term "servitization" has been established by Vandermerwe and Rada [5] and characterizes the change of the producers business model from product sales towards the conversion of service offers along the entire product lifecycle. These service offerings can be both product extending as well as product maintaining (e.g. MRO). Servitization can be pursued due to different reasons of economic, environmental or strategic perspectives. [6] For knowledge intensive products servitization (by the producer) is traditionally a wide spread approach to supplying the customer with the through-life services he and his product need. Marine auxiliaries can be included in this consideration as they regularly have to fulfill strict regulations both in production as well as during service.

\subsection{Digitized Products}

The process of collecting, storing and analysing data from customers and end-users of products and services with the goal to discover new needs or identify changes in usage patterns is called informatization by [7]. Informatization is done to enhance existing offers or the related service-level agreements (SLAs) back to the customer. [7] systematise this process as an information feedback loop beginning with collecting and storing data from customers, analysing it to create data about them, and providing information about new service offerings back to the customer, after which the loop is repeated. As systems of product-services (PSS) are seldom provided by an individual company, and the economics of scale in the networked economy stem from the size of the supporting network [8], multiple information feedback loops are opened amongst the stakeholders in the PSS network.

One emerging source of information for these feedback loops is the result of the increasing digitalization of products, services and PSS. According to [9], digitalized products are those, which have seven material properties: programmability, addressability, senseability, memorability, communicability, traceability, and associability. This enables a loose coupling across the four layers of a digital service architecture, which includes devices, networks, services and contents. Other authors have previously developed concepts for "digitalized" products, such as smart or intelligent products. These are physical products which may be transported, processed or used and which comprise the ability to act in an intelligent manner. McFarlane et al. define the Intelligent Product as "a physical and information based representation of an item [...] which possesses a unique identification, is capable of communicating effectively with its environment, can retain or store data about itself, deploys a 
language to display its features, production requirements, etc., and is capable of participating in or making decisions relevant to its own destiny." [10] The degree of intelligence an intelligent product may exhibit varies from simple data processing to complex pro-active behaviour [11]. Digitized or intelligent products can thus make use e.g. of RFID, sensors and embedded computing to collect information about their usage, service, maintenance, upgrading, decommissioning and disposal throughout their lifecycles and feed it back to stakeholders responsible for the PSS offer.

\subsection{IoT - Internet of Things}

The product services of the $21^{\text {st }}$ century are broadly supported by and reliant on the internet [12]. This trend is dramatically increased by the possibilities of the Internet of Things (IoT).

The Internet of Things can be seen as an evolution of the "old" human driven internet towards an internet which is driven by inanimate objects - things [13]. Originating in the wake of radio frequency identification (RFID) technology the IoT encompasses every object that participates in data exchange with other systems. It does not make any difference whether this exchange is multilateral or not, neither what sort of system is observed. [14] In practice this means, that both embedded systems with advanced on-board intelligence as well as simple data processing or forwarding can be part of the internet of things as long as data exchange is conducted automatically.

\subsection{AIS - Automatic Identification System}

The Automatic Identification System (AIS) for ships was developed as a system to make ship traffic safer by avoiding accidents due to human errors or technological insufficiencies like impaired radar sight. $[15,16]$ The International Maritime Organisation issued a guideline for its use in 2002 [17] and thus forced the mass introduction of the system.

The AIS messages are sent automatically at a defined interval and can be received and read by anyone within the proximity of the sender as the VHF radio technology is used. Typically, a range of 10 to 20 nautical miles can be reached but this strongly depends on the hardware choice and geographical parameters. [18] The standardized AIS messages convey information about the ship, its position and also its current voyage [15].

Since its initial development one and a half decades ago both the capabilities and uses of the AIS have been constantly extended. For example, satellite based AIS (SAIS) can now also cover the oceans beyond the reach of shore based receivers [19]. The data which is being generated by hundreds of thousands of ships every minute is also put to use in increasingly various fashions. From collision avoidance systems [20] over marine traffic engineering and harbour traffic management [21] to homeland security applications [22], [23] the applications are still mostly confined to the original idea of AIS - increasing security, safety and efficiency of the vessel and the traffic system. 


\section{$4 \quad$ Methodology}

This section describes the methodology used to address the problem stated in the second chapter by applying the technologies and concepts introduced in the preceding section.

\subsection{Approach}

A six step approach was chosen and prototypically implemented in a use case. Fig. 1 below gives an overview of the process.

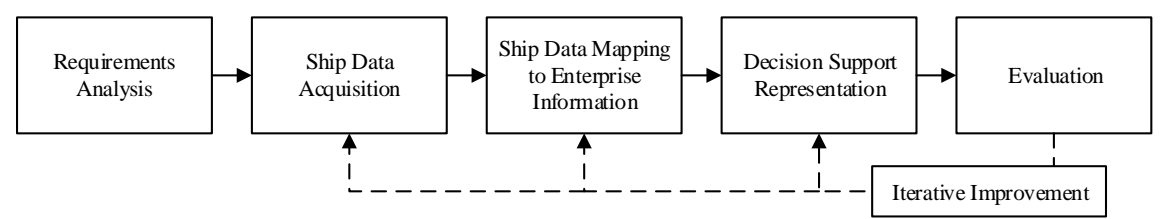

Fig. 1. Block Diagram of the chosen Methodology

The following subsections illustrate the use case and the steps taken during prototypical implementation.

\subsection{Use Case}

TeamTec AS is a Norwegian producer of marine auxiliaries. Its main products are incinerators for on-board waste treatment, stripping ejectors (fluid driven jet pumps) and ballast water treatment system. It has over 30 years of history and thousands of products installed on ships worldwide. The TeamTec incinerators are high knowledge products which are serviced only by TeamTec or affiliated service providers. With a very high number of concerned shipowning companies the administrative effort to coordinate MOL activities on their products is immense. While TeamTec has for many years been recording information from all lifecycle phases about their products on item-level, the access to updated information regarding the containing ship is completely manual up to now.

The available lifecycle data is managed in an ERP system but the ships schedules are retrieved manually from various AIS based internet services and compiled in spreadsheets to be followed up on.

\subsection{Prototypical Implementation}

The implementation process at TeamTec was conducted during the research project "Innovativ Kraft" funded by the Research Council of Norway, following the steps presented in section 4.1 . 
Requirements Analysis. During several meetings the requirements towards the DSS were recorded. Involved were the process owners and experts for information technology and industrial process design. The identified main objectives for the DSS are summarized in the following table together with their criticality.

Table 1. Summary of Main Objectives identified during Requirements Analysis.

\begin{tabular}{lll}
\hline Objective No. & Objective Content & Criticality \\
\hline O1 & Information about next Port of Call & High \\
O2 & Information about Estimated Time of Arrival & High \\
O3 & Search / Order by IMO Number & Medium \\
O4 & Flexible Data Mapping with Enterprise Data & High \\
O5 & Low Total Cost of Ownership & Low \\
O6 & Data Ownership & Medium \\
\hline
\end{tabular}

In a feasibility study it was found that the three objectives with regards to the data content (O1-O3) can be achieved by the use of AIS data. It was also found, that the three technical objectives (O4-O6) can be best implemented in an individual server application, which can be operated via a web user interface.

Ship Data Acquisition. The commercial access to AIS data streams is as previously stated regularly linked to a substantial recurring fee to other internet service providers. As the relevant AIS information (see table 1, O1 \& O2) are rather static during a single voyage, uniform AIS coverage over the whole sea surface is not required in this use case. Thus the utilization of a S-AIS services is not needed. After a market analysis it was decided to join the AISHub Data Sharing Network ${ }^{2}$.
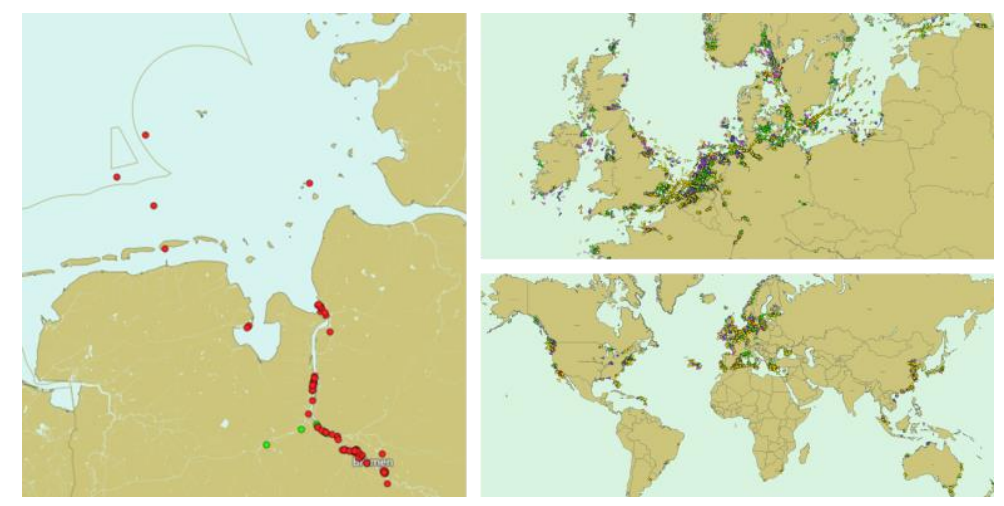

Fig. 2. Coverage Maps of the BIBA feed (left) and the AISHub feed (right)

By providing one AIS data stream to the AISHub any member gains access to the combined stream of all members' receivers, providing access to AIS data concerning

\footnotetext{
2 http://www.aishub.net/
} 
over 23500 vessels including the rights to commercial use of the data. Figure 2 shows the coverage of both the BIBA AIS station as well as the AISHub total feed.

Due to its inland location for the BIBA AIS station, a directional antenna was chosen together with an internet enabled receiver which forwards the received data from the AIS radio system to the AISHub servers.

The incoming data is filtered for the relevant ships and stored in a database.

Ship Data Mapping to Enterprise Information. The identification of the relevant ships is based on the company database which holds the IMO number as means of identification of the product containing ship. Against this data set, which is updated once new ships have been added to the ERP system, the incoming AIS stream will be compared and only the messages concerning the relevant ships is further processed.

The stored information from the ERP system and the AIS system are linked via the project reference. On the ERP system it links to all information regarding the product and its lifecycle data, while on the AIS system it links to the installation and subsequently to the ship. However, it must be noted, that this is a n-1 relationship, as one ship can have multiple installations.

Decision Support Representation. From the combined information a number of views can be generated. At the current state three main views have been implemented:

The vessel list view gives an overview of the vessels registered in the system with some details for vessel identification and the project reference. It also allows manual editing and the addition and removal of vessels. Figure 3 gives an example of this view.

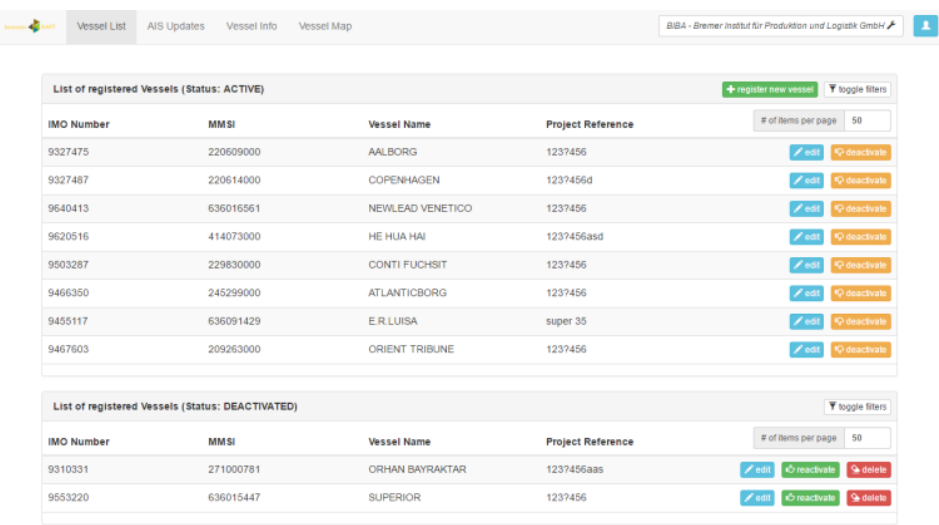

Fig. 3. Screenshot of the vessels listings.

The vessel information view shows the current AIS data sets for the vessels and gives information about the current location, next port of call and estimated time of arrival of the vessel.

Finally, the vessel map gives an overview of the positions of all selected ships on a world map. This map can also be adjusted to show the next destinations of the ships. 
Furthermore, a heat map layer can be activated on the map, to allow for easy analysis of the main areas of travel of the company's products. Figure 4 gives an example of the heat map view.

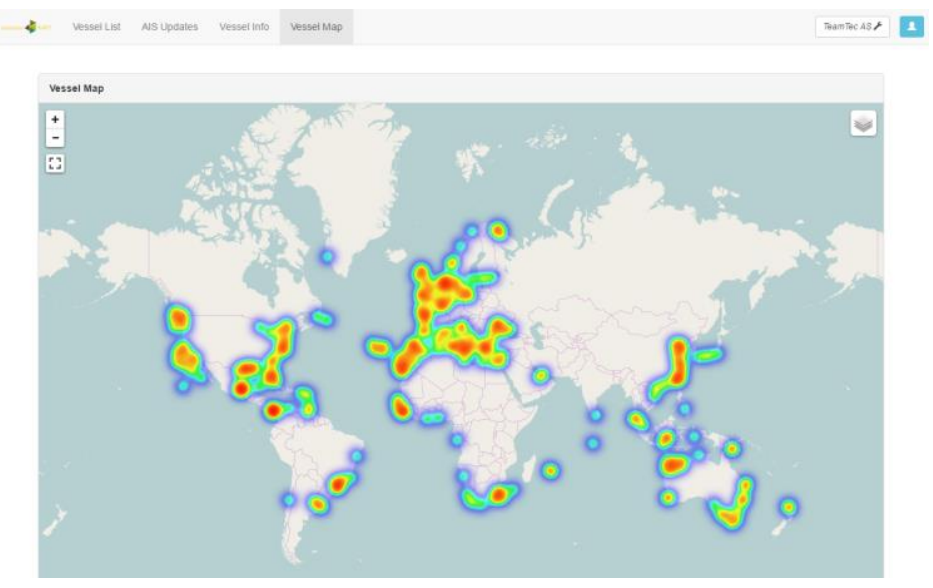

Fig. 4. Screenshot of the current positions of approximately 6000 selected vessels displayed as heat map.

Filters can be applied on all views to allow for quick navigation even in large amounts of data.

Evaluation and Iterative Improvement. For the evaluation of the system the progress of the development has been presented during multiple meetings. The feedback was collected and included in the ongoing development process.

\section{$5 \quad$ Results}

The ongoing evaluation of the system has shown that the system presented has the potential of significant improvements in both efficiency and resource effectivity. The objectives set at the beginning of the implementation can be met throughout.

It is estimated that for TeamTec the productive implementation would save multiple hours of daily work time. More important however it would allow for a better customer service due to easily enabling coordinated requests to the shipowning companies and a significant decrease in maintenance personnel travels.

\section{Conclusion and Outlook}

This paper has documented the methodological approach to the problem of middle-oflife actions (MOL) management for marine auxiliaries producers. The producers face 
the challenge, that they need to adapt their maintenance activities to the otherwise defined but miscommunicated schedules of the ships, which are carrying their products. The presented system provides a solution utilizing the Internet of Things (IoT) and the data that is constantly being produced by the ships through the Automatic Identification System (AIS).

The system evaluations have found that the system holds significant potential for the use case companies as most likely also for many other companies in the sector, However, from the prototypical implementation presented in this paper to the productive implementation some further adjustments need to be made.

Furthermore, the identification of further going objectives has already begun. One research topic to be considered is how the solution can be best applied to a group of companies in order to leverage the effects of joint MOL actions. From the data analytics point of view, it can also be investigated how the MOL actions management can be further optimized by including historical data from the ships.

Another research direction will be how to extend the basic IoT functionalities that are being used in the system at the moment to the use of product embedded information devices which can supply product state information. This could greatly enhance the current solution and enable more effective and efficient MOL actions like predictive maintenance.

Acknowledgments. This work was partially funded by The Research Council of Norway within the project "Innovativ Kraft" (project no. 235708). The authors would like to thank TeamTec AS for the support and openness in the preparation of this paper.

\section{References}

1. Sundin E (2009) Life-cycle perspectives of product/service-systems: in design theory. In: Introduction to product/service-system design. Springer, pp 31-49

2. Kiritsis D, Bufardi A, Xirouchakis P (2003) Research issues on product lifecycle management and information tracking using smart embedded systems. Advanced Engineering Informatics 17:189-202.

3. Hribernik KA, von Stietencron M, Hans C, Thoben K-D (2011) Intelligent Products to Support Closed-Loop Reverse Logistics. Glocalized Solutions for Sustainability in Manufacturing 486-491.

4. Jun HB, Kiritsis D, Xirouchakis P (2007) Research issues on closed-loop PLM. Computers in industry 58:855-868.

5. Vandermerwe S, Rada J (1989) Servitization of business: adding value by adding services. European Management Journal 6:314-324.

6. Neely A (2009) Exploring the financial consequences of the servitization of manufacturing. Oper Manag Res 1:103-118. doi: 10.1007/s12063-009-0015-5

7. Opresnik D, Hirsch M, Zanetti C, Taisch M (2013) Information - The Hidden Value of Servitization. In: Prabhu V, Taisch M, Kiritsis D (eds) Advances in Production Management Systems. Sustainable Production and Service Supply Chains. Springer Berlin Heidelberg, pp 49-56

8. Kelly K (1999) New rules for the new economy. Penguin 
9. Yoo Y, Henfridsson O, Lyytinen K (2010) Research commentary-The new organizing logic of digital innovation: An agenda for information systems research. Information systems research 21:724-735.

10. McFarlane D, Sarma S, Chirn JL, Wong CY, Ashton K (2003) Auto ID systems and intelligent manufacturing control. Engineering Applications of Artificial Intelligence 16:365-376. doi: http://dx.doi.org/10.1016/S0952-1976(03)00077-0

11. Kärkkäinen M, Holmström J, Främling K, Artto K (2003) Intelligent products - a step towards a more effective project delivery chain. Computers in Industry 50:141-151. doi: http://dx.doi.org/10.1016/S0166-3615(02)00116-1

12. Thoben K-D, Wortmann JC (Hans) (2012) The Role of IT for Extended Products' Evolution into Product Service Ecosystems. In: Emmanouilidis C, Taisch M, Kiritsis D (eds) Advances in Production Management Systems. Competitive Manufacturing for Innovative Products and Services. Springer Berlin Heidelberg, pp 399-406

13. Ashton K (2009) That "internet of things" thing. RFiD Journal 22:97-114.

14. Atzori L, Iera A, Morabito G (2010) The internet of things: A survey. Computer networks 54:2787-2805.

15. Harati-Mokhtari A, Wall A, Brooks P, Wang J (2007) Automatic Identification System (AIS): Data Reliability and Human Error Implications. The Journal of Navigation 60:373-389. doi: 10.1017/S0373463307004298

16. IALA (2003) IALA Technical Clarifications on ITU Recommendation ITU-R M.13711, Edition 1.4.

17. IMO - INTERNATIONAL MARITIME ORGANIZATION (2002) GUIDELINES FOR THE ONBOARD OPERATIONAL USE OF SHIPBORNE AUTOMATIC IDENTIFICATION SYSTEMS (AIS).

18. Eriksen T, Høye G, Narheim B, Meland BJ (2006) Maritime traffic monitoring using a space-based AIS receiver. Acta Astronautica 58:537-549. doi: 10.1016/j.actaastro.2005.12.016

19. Narheim B, Olsen O, Helleren O, Olsen R, Beattie A, Zee R (2008) A Norwegian Satellite for Space-based Observations of AIS in the High North. AIAA/USU Conference on Small Satellites

20. Mou JM, Tak C van der, Ligteringen H (2010) Study on collision avoidance in busy waterways by using AIS data. Ocean Engineering 37:483-490. doi: 10.1016/j.oceaneng.2010.01.012

21. Lin C, Dong F, Le J, Wang G (2008) AIS System and the Applications at the Harbor Traffic Management. In: 4th International Conference on Wireless Communications, Networking and Mobile Computing, 2008. WiCOM '08. pp 1-3

22. Zhu F (2011) Mining ship spatial trajectory patterns from AIS database for maritime surveillance. In: 2011 2nd IEEE International Conference on Emergency Management and Management Sciences (ICEMMS). pp 772-775

23. Tetreault BJ (2005) Use of the Automatic Identification System (AIS) for maritime domain awareness (MDA). In: Proceedings of MTS/IEEE OCEANS, 2005. p 15901594 Vol. 2 